\title{
EFEITO DA TENACIDADE DA FIBRA SOBRE PROPRIEDADES TECNOLÓGICAS DO FIO DE ALGODÃO $\left({ }^{1}\right)$
}

\author{
NELSON PAULIERI SABINO $\left({ }^{2,3}\right)$, JULIO ISAO KONDO $\left(^{2}\right)$ \\ e ROSE MARRY ARAÚJO GONDIM-TOMAZ ${ }^{2}$ )
}

\begin{abstract}
RESUMO
Consideraram-se três variedades de algodão com valores de tenacidade da fibra variando de 20,5 a $22,2 \mathrm{~g} / \mathrm{Tex}$ : IAC 16 , IAC 13-1 e IAC 17 , classificadas, respectivamente, como de alta, média e baixa tenacidade. Tais variedades apresentaram características tecnológicas semelhantes quanto a comprimento, uniformidade de comprimento, índice de finura Micronaire e maturidade. As amostras foram processadas em estabelecimentos industriais, da maneira convencional, produzindo, cada uma, fios de títulos Ne20, Ne30 e Ne40. Para cada título, empregaram-se sete coeficientes de torção, representados pelas constantes $3,4,3,6,3,8,4,0,4,2,4,5$ e 4,7. Efetuaram-se as análises da variância dos resultados, de acordo com o delineamento fatorial 3 $\times 3 \times 7$, representado pelas três variedades, pelos três títulos e pelos sete níveis de coeficientes de torção. Mediante os resultados, conclui-se que fibras de algodão com alta tenacidade produzem fios mais resistentes e elásticos do que aquelas de baixa tenacidade, para qualquer título ou torção. A quantidade de torçōes requeridas para a obtenção de máxima resistência dos fios de algodão é pouco afetada pela tenacidade da fibra. Os fios de títulos mais altos têm os menores valores de tenacidade e elongação. A variedade IAC 16 apresentou fios com os maiores valores de tenacidade, seguida da 'IAC 13-1' e da 'IAC 17', e fios mais elásticos, acompanhada da 'IAC 17 ' e da 'IAC 13-1'.
\end{abstract}

Termos de indexação: algodão, Gossypium hirsutum L., tenacidade da fibra, torção, fiação, tenacidade e título do fio.

(1) Trabalho apresentado na V Reunião Nacional de Algodão, realizada em Campina Grande (PB), de 24 a 28 de outubro de 1988 Recehido para publicação em 18 de julho de 1994 e aceito em 7 de fevereiro de 1995.

( ${ }^{2}$ ) Seção de Tecnologia de Fibras, Instituto Agronômico (IAC), Caixa Postal 28. 13001-970 Campinas (SP).

(3) Com bolsa de pesquisa do CNPq 


\title{
ABSTRACT \\ EFFECT OF THE COTTON FIBER STRENGTH ON YARN PROPERTIES
}

\begin{abstract}
Three cottons with fiber strength of $20.5,20.9$ and $22.2 \mathrm{~g} / \mathrm{Tex}$ and having other important fiber properties approximately equal were selected. The cottons were processed on conventional processing equipment into $20 / 1,30 / 1$ and $40 / 1$ yarn counts, using a range of twist multipliers of $3.4,3.6,3.8,4.0,4.2,4.5$ and 4.7. Yarn strength and elongation determinations were made on a pendulum-type tester of 150-300 lbs capacity. It was found that: 1 - High strength cotton produced stronger yarns than low strength for any given yarn count or twist; 2 - The amount of twist required to obtain maximum strength was not affected significantly by fiber strength; 3 - High fiber strength produced yarns with better elongation and 4 The IAC 16 cotton variety yielded yarns of highest tenacity and elongation.
\end{abstract}

Index terms: cotton, Gossypium hirsutum L., fiber strength, twist, yarn strength, spinning, yarn count.

\section{INTRODUÇÃO}

A tenacidade e a elongação, componentes fundamentais de avaliação da qualidade do fio de algodão, são afetadas diretamente pelas principais propriedades tecnológicas da fibra. Embora as relações entre essas componentes sejam pronunciadas e parcialmente genéticas, ambas estão sujeitas a apreciáveis variações nos seus valores, pelo efeito do ambiente.

Para a análise e avaliação da qualidade dos fios, deve-se também levar em consideração outros fatores, principalmente o título e o número de torções aplicados na sua confecção. Entende-se por título a medida que caracteriza a relação existente entre o peso e o comprimento, e que, pelo sistema inglês (Ne), representa o número necessário de 840 jardas (1 hank) de fio para atingir uma libra. Na fiação industrial de algodão cardado, a gama de títulos mais utilizada está compreendida entre Ne6 e Ne40; quanto maior for esse número, mais fino será o fio (Grove \& Hamby, 1960).

A torção exerce grande influência na tenacidade e na elongação do fio e é comumente expressa em torçôes por polegada ou por metro. O número de torçôes corresponde ao produto do coeficiente de torção $\left(\alpha_{\mathrm{e}}\right)$ pela raiz quadrada do título inglês $(\mathrm{Ne})$.
O coeficiente de torção baseia-se no ângulo em que as fibras de algodão se apresentam em relação ao eixo do fio. Os fios grossos, assim como os finos, podem utilizar o mesmo coeficiente.

Por outro lado, comprimento, finura, tenacidade, uniformidade de comprimento e porcentagem de fibras maduras exercem significativa influência na tenacidade e elongação dos fios de algodão, com diferentes graus de amplitude. Segundo Webb \& Richardson (1945), conclui-se que, das cinco propriedades citadas, existe forte evidência de que a tenacidade da fibra seja o mais importante fator de melhoria da tenacidade do fio de títulos Ne22 a Ne60. Corroborando tais resultados, Fiori et al. (1954) demonstraram que fios de títulos Ne12, $\mathrm{Ne} 22, \mathrm{Ne} 36$ e Ne50, com baixa torção, produzidos com algodão de alta tenacidade de fibra, foram 35 $40 \%$ mais resistentes do que aqueles confeccionados com algodão de baixa tenacidade. Landstreet (1954) relatou que, para fios produzidos com um valor ótimo de torção, a tenacidade da fibra contribuiu com cerca de $88 \%$ para a dos fios.

Mediante variedades paulistas de algodoeiro, este estudo objetivou analisar os efeitos da tenacidade da fibra sobre a tenacidade e a elongação de fios de títulos $\mathrm{Ne} 20, \mathrm{Ne} 30$ e $\mathrm{Ne} 40$, em vários níveis de torção. 


\section{MATERIAL E MÉTODOS}

Selecionaram-se amostras de três variedades de algodoeiro com valores de tenacidade da fibra entre 20,5 e $22,2 \mathrm{~g} / \mathrm{Tex}$ e as outras características tecnológicas - comprimento, uniformidade de comprimento, índice de finura Micronaire e maturidade com valores semelhantes. As amostras, representativas das variedades paulistas IAC 16, IAC 13-1 e IAC 17, selecionadas, respectivamente, como de alta, média e baixa tenacidade da fibra, e com peso aproximado de $200 \mathrm{~kg}$ cada uma, foram obtidas nos campos de multiplicação de sementes localizados nas Estações Experimentais de Tietê, Tatuí e Mococa.

Quanto à análise das propriedades tecnológicas da fibra: (a) obteve-se, no fibrógrafo digital, o valor médio, em milímetros, de 2,5\% para o comprimento, a partir de cinco determinações em cada amostra; (b) a uniformidade de comprimento, expressa em porcentagem, foi a relação dos valores dos comprimentos 50 e $2,5 \%$, fornecidos pelo fibrógrafo em cinco repetições; (c) o índice de finura, que representa a finura da fibra, quando são iguais as condições de maturidade, foi fornecido pelo aparelho Fibronaire por meio de duas determinações por amostra (American Society for Testing and $\mathrm{Ma}-$ terials, 1963); (d) o grau de maturidade foi determinado no fibrógrafo digital, conforme método proposto por Gridi-Papp \& Sabino (1972), a partir de cinco determinações feitas por amostra; (e) os valores de maturidade 11,0 e 14,0 correspondem, respectivamente, a 82 e $64 \%$ de fibras maduras determinadas pelo método da soda cáustica a $18 \%$; (f) a tenacidade da fibra, obtida no aparelho Pressley, é expressa em g/Tex - índice que corresponde ao número de gramas-força necessário para romper uma mecha padrão de fibras de título internacional de 1 Tex (Tex é a massa em gramas de 1.000 metros de material), quando a distância entre as garras do aparelho é de $1 / 8$ de polegada. Realizaram-se quatro determinações por amostra.

Os algodões das amostras foram processados em estabelecimentos industriais, da maneira convencional, utilizando-se, nas diversas fases do processamento, os seguintes equipamentos: linha de abertura dos fardos; batedor; carda; passadeira (duas passagens); maçaroqueira e filatório. Até a segunda passagem na passadeira, prepararam-se as amostras, uma de cada vez, e, nas demais etapas, em conjunto, produzindo, cada uma, fios de títulos $\mathrm{Ne} 20, \mathrm{Ne} 30$ e Ne40. Para cada título produzido no filatório, empregaram-se sete coeficientes de torção $\left(\alpha_{\mathrm{e}}\right)$, representados pelas constantes: $3,4,3,6$, $3,8,4,0,4,2,4,5$ e 4,7 , as quais significam a relação entre o número de torções por polegada e as raízes quadradas respectivas de título dos fios produzidos.

Após a confecção dos fios, retiraram-se, ao acaso, dez espulas de cada variedade com o respectivo título e coeficiente de torção, para as análises das propriedades tecnológicas nos Iaboratórios da Seção de Tecnologia de Fibras. Os resultados de tenacidade e elongação foram obtidos em um dinamômetro pendular, que utiliza meadas de 120 jardas, tendo sido efetuados vinte arrebentamentos por tipo de fio, isto é, dois em cada espula. A tenacidade do fio, expressa em RKM, representa o comprimento do fio em quilômetros, necessário para provocar, devido a seu próprio peso, a sua ruptura. A elongação, em porcentagem, significa o alongamento do fio até o momento do arrebentamento.

Efetuaram-se as análises estatísticas dos resultados das propriedades tecnológicas dos fios produzidos de acordo com o delineamento fatorial 3 x $3 \times 7$, representado pelas três variedades, pelos três títulos de fio ( $\mathrm{Ne}$ ) e pelos sete níveis de coeficientes de torção ( $\alpha$ e).

\section{RESULTADOS E DISCUSSÃO}

No quadro 1, encontram-se os resultados médios das características tecnológicas da fibra relativos às três variedades paulistas de algodoeiro: IAC 16, IAC 13-1 e IAC 17.

Observa-se, de modo geral, que as características apresentam valores semelhantes entre si, quanto ao comprimento $2,5 \%$, à finura Micronaire, à maturidade e à uniformidade de comprimento das fibras, ocorrendo variações quanto à tenacidade. De fato, as variedades IAC 13-1 e IAC 16 mostraram resultados, respectivamente, de 2,0 e $8,3 \%$ maiores que os da IAC 17, utilizada, neste estudo, como referência de comparação. 
Pelo quadro 2 - dados médios de tenacidade obtidos nos fios produzidos com a utilização das três variedades de algodão em três títulos diferentes e sete níveis de torção, assim como as respectivas análises estatísticas - observam-se valores de $\mathrm{F}=$ $37,13^{* *}$ para os diferentes coeficientes de torção; $\mathrm{F}=546,97 * *$ para títulos; $\mathrm{F}=1.040,59 * *$ para variedades e $\mathrm{F}=9,15^{* *}$ para a interação coeficientes

Quadro 1. Propriedades tecnológicas da fibra de três variedades paulistas de algodoeiro

\section{Propriedades tecnológicas}

Comprimento $2,5 \%(\mathrm{~mm})$

Uniformidade de comprimento $(\%)$

Finura Micronaire (índice)

Maturidade (\%)

Tenacidade "Pressley" (g/Tex)

\section{Variedades}

\begin{tabular}{lcc}
\hline IAC 16 & IAC $13-1$ & IAC 17 \\
26,0 & 26,2 & 26,2 \\
44,6 & 42,7 & 43,0 \\
4,2 & 4,2 & 4,3 \\
66,9 & 67,4 & 67,0 \\
$22,2 \mathrm{~b}\left({ }^{1}\right)$ & $20,9 \mathrm{a}$ & $20,5 \mathrm{a}$ \\
\hline
\end{tabular}

$\left({ }^{1}\right)$ Médias com letras comuns não diferem entre si pelo teste de Tukey a $5 \%$ de probabilidade.

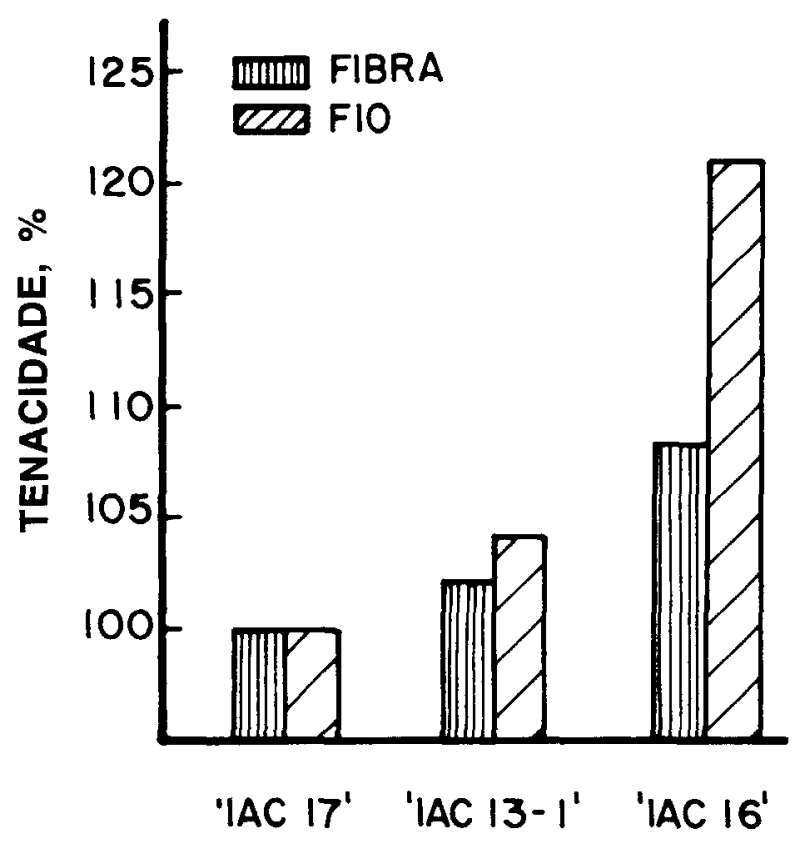

Figura 1. Diferenças na tenacidade da hibra e do fio das variedades IAC $13-1$ e IAC 16, quando comparadas com a 'IAC 17'.

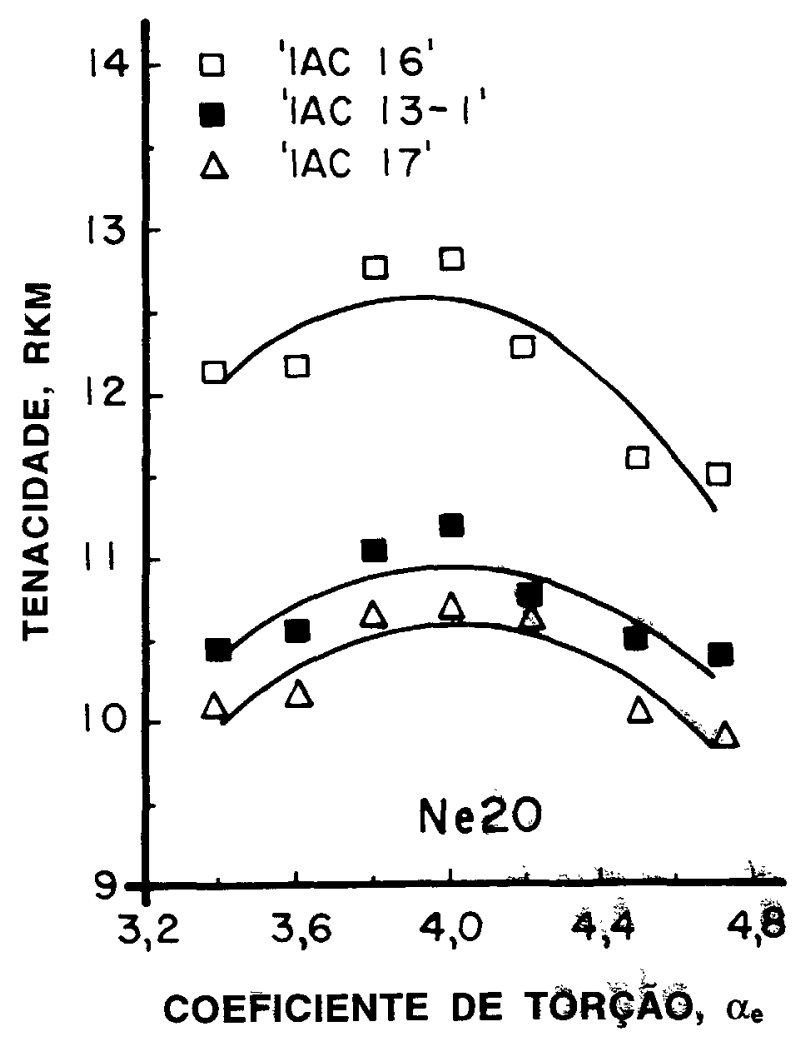

Figura 2. Representaçāo gráfica das equaçōes de regressão e valores experimentais para ténacidade, relativa ao título $\mathrm{Ne} 20$. 


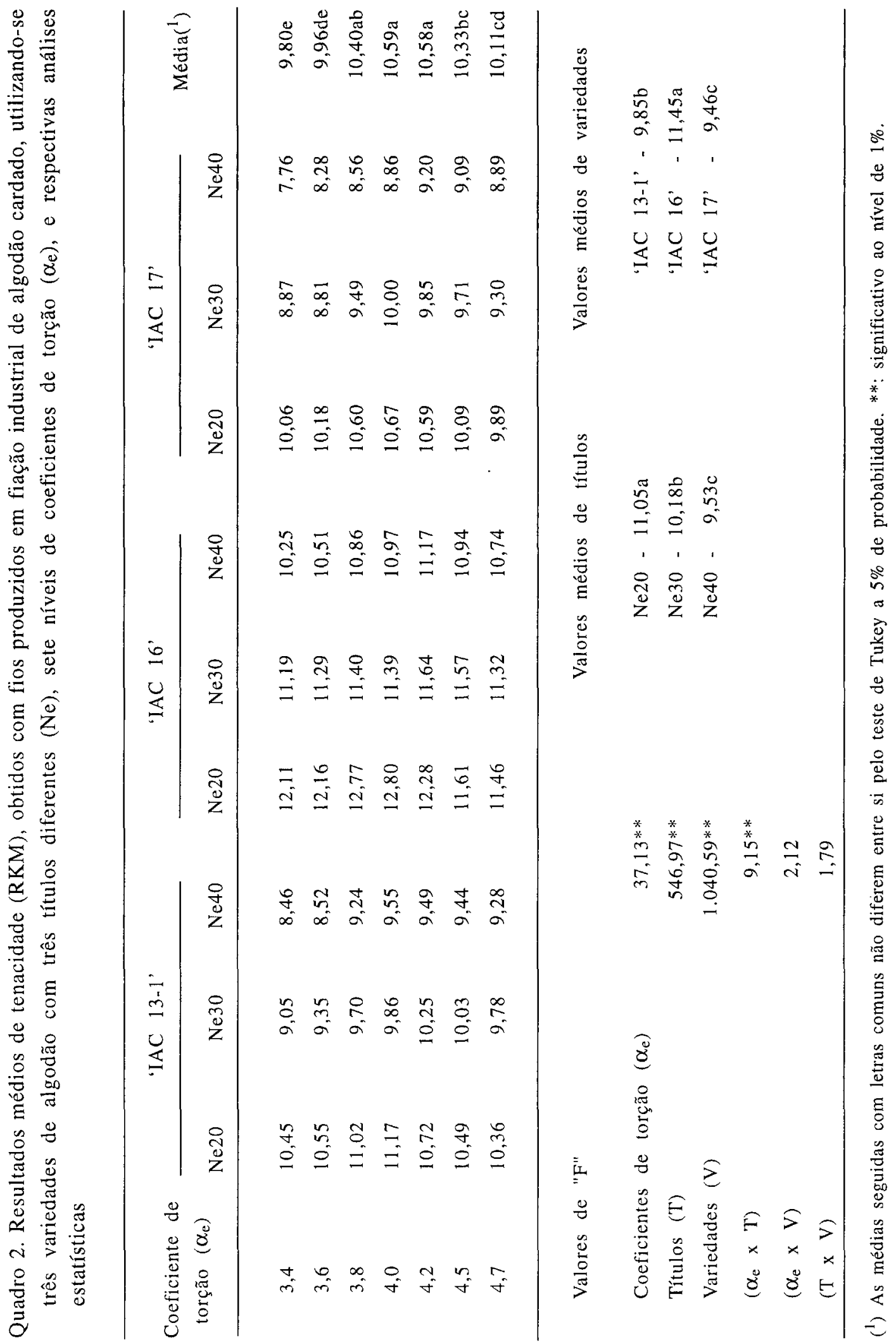




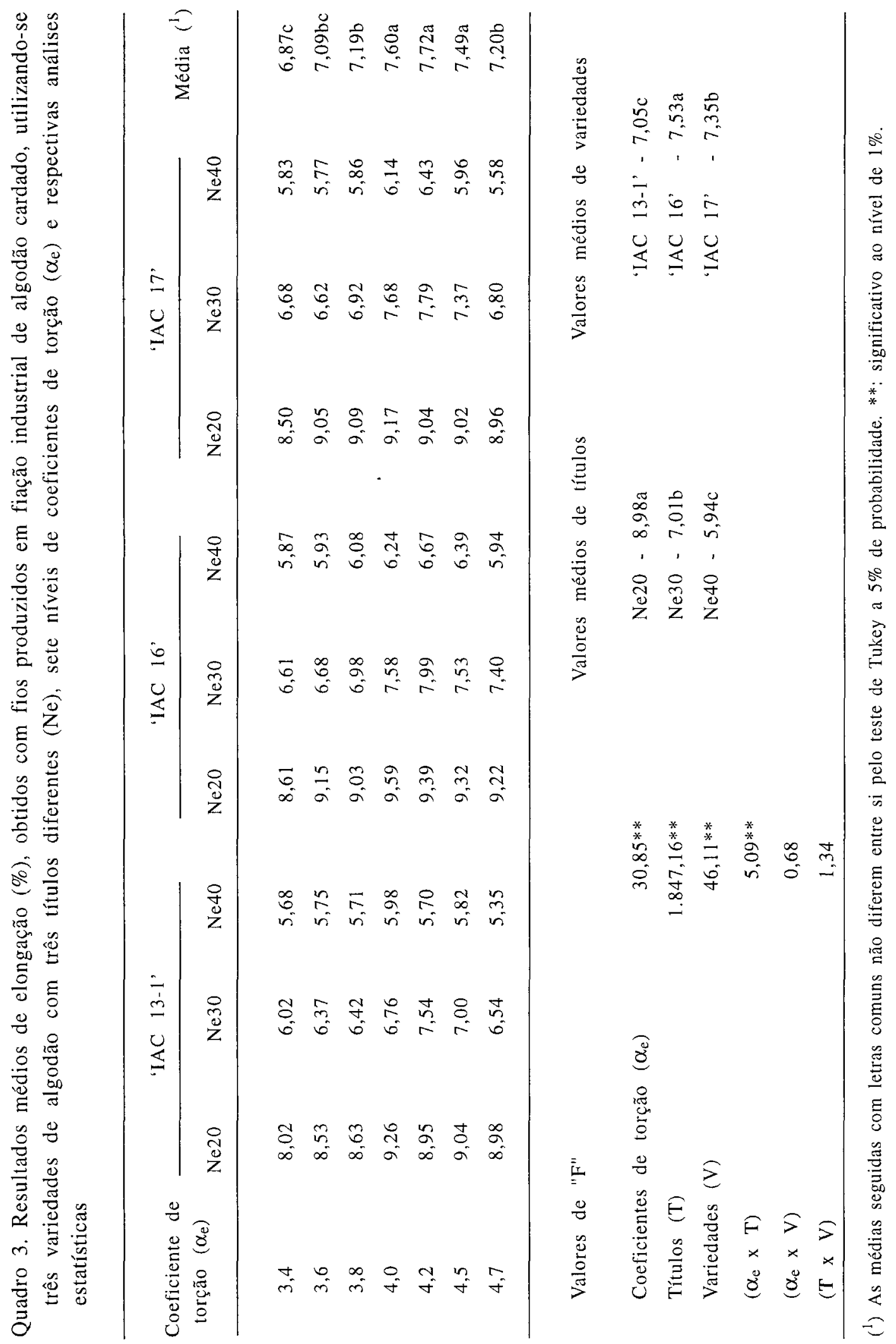


de torção $\mathrm{x}$ títulos. Os valores médios dos níveis de torção, envolvendo as três variedades e títulos, demonstram que a máxima tenacidade (RKM) foi obtida na faixa de 3,8 a 4,2 e a menor, na de 3,4 a 3,6. O fio de título mais grosso (Ne20) foi o mais resistente (11,05 RKM), decrescendo para o mais fino (Ne40), cujo valor foi de 9,53 RKM.

As variedades também apresentaram valores diferentes, destacando-se a 'IAC 16', que produziu o fio mais resistente (11,45 RKM), vindo a seguir a 'IAC 13-1' (9,85 RKM), respectivamente 21,0 e $4,1 \%$ superiores à 'IAC 17 ' (9,46 RKM), de menor tenacidade do fio. Esses últimos resultados podem ser mais bem visualizados na figura 1, que mostra, também, uma diferença menor no que diz respeito à tenacidade da fibra: de 2,0 e $8,3 \%$ para a 'IAC 13-1' e 'IAC 16' respectivamente.

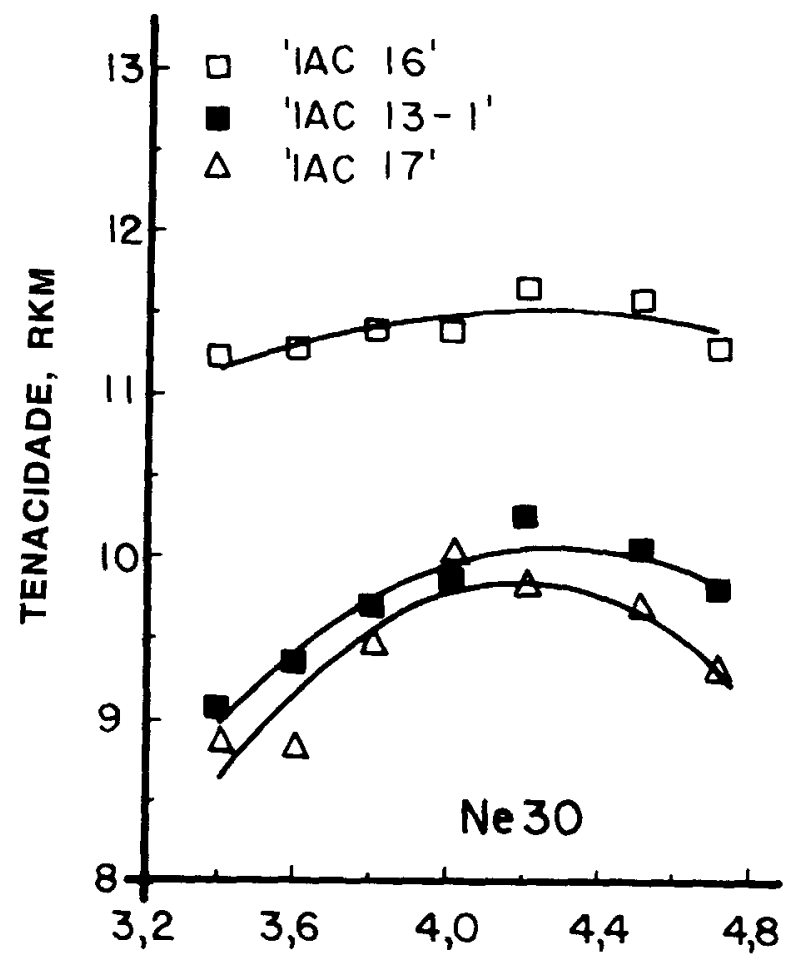

COEFICIENTE DE TORÇÃO, $\alpha_{e}$

Figura 3. Representação gráfica das equações de regressão e valores experimentais para tenacidade, relativa ao título Ne30.
O quadro 3 registra os resultados médios de elongação (\%) dos fios produzidos pelas três variedades em três títulos diferentes e sete níveis de torção, assim como as respectivas análises estatísticas. Os valores médios de elongação apresentaram diferenças significativas para os coeficientes de torção utilizados $\left(\mathrm{F}=30,85^{*}\right)$, tendo sido obtidos os valores mais altos na faixa de 4,0 a 4,5 , e os mais baixos, na de 3,4 a 3,6. Em função do título, a maior elongação foi de $8,98 \%$ (Ne20), decrescendo para o título mais fino (Ne40), com $5,94 \%$. Os resultados médios para as variedades comprovaram que o fio mais elástico foi alcançado com a variedade IAC $16(7,53 \%)$, seguida da 'IAC 17 ' $(7,35 \%)$ e 'IAC $13-1$ ' $(7,05 \%)$.

Tanto para a tenacidade quanto para a elongação dos fios confeccionados, observaram-se interações

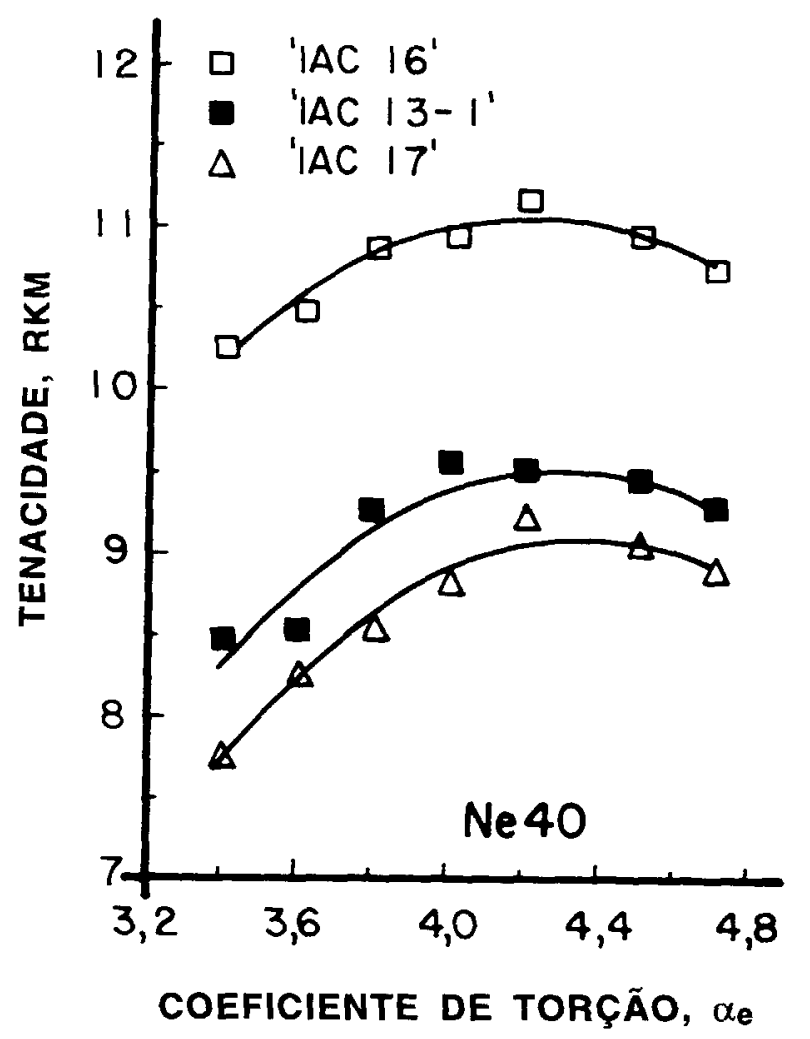

Figura 4. Representação gráfica das equações de regressão e valores experimentais para tenacidade, relativa ao título Ne 40 . 
significativas para coeficiente de torção $\mathrm{x}$ título de fio - Quadros 2 e 3. Tais interações podem ser explicadas pelos valores máximos de tenacidade e de elongação, conseguidos em faixas diferentes de coeficientes de torção para cada título de fio produzido.

As médias observadas permitem admitir que as variações da tenacidade e da elongação do fio seguiram curvas de segundo grau. Dessa forma, estimaram-se nove equações de regressão para tenacidade e nove para elongação, através das quais calcularam-se os coeficientes de torção correspondentes aos máximos valores de tenacidade e de elongação dos fios manufaturados - Quadro 4. Os maiores valores de elongação foram conseguidos para as variedades e títulos utilizados na faixa de 3,95 a $4,34 \alpha_{\mathrm{e}}$.

Quadro 4. Resultados de coeficientes de torção $\left(\alpha_{e}\right)$ obtidos para os maiores valores de tenacidade (RKM) e elongação (\%) em função das diversas equações de regressão, utilizando fios de diferentes títulos produzidos por três variedades, em fiação industrial de algodão cardado

\begin{tabular}{llc}
\hline \multirow{2}{*}{$\begin{array}{l}\text { Variedades } \\
\text { e Títulos }\end{array}$} & \multicolumn{2}{c}{ Propriedades do fio } \\
\cline { 2 - 3 } 'IAC 13-1' & & \\
Nenacidade (RKM) & Elongação (\%) \\
Ne 30 & 4,01 & 4,30 \\
Ne 40 & 4,30 & 4,25 \\
'IAC 16' & 4,29 & 4,15 \\
Ne 20 & & \\
Ne 30 & 3,91 & 4,24 \\
Ne 40 & 4,24 & 4,34 \\
'IAC 17' & 4,21 & 4,17 \\
Ne 20 & & \\
Ne 30 & 4,01 & 3,95 \\
Ne 40 & 4,20 & 4,17 \\
\hline
\end{tabular}

A representação gráfica das equaçōes de regressão e os valores médios experimentais para a tenacidade e elongação, envolvendo as três variedades em função dos três títulos e dos coeficientes de torção, encontram-se nas figuras 2 a 7 .

As figuras 2, 3 e 4 mostram os efeitos, respectivamente, da tenacidade da fibra sobre a tenacidade dos fios de títulos $\mathrm{Ne} 20, \mathrm{Ne} 30$ e $\mathrm{Ne} 40$. A variedade IAC 16 sempre produziu o fio mais resistente, seguida da 'IAC 13-1' e da 'IAC 17', para todos os títulos e coeficientes de torção. As curvas que representam o coeficiente de torção-tenacidade, de forma quadrática para as três variedades, foram similares. Utilizando como referência o menor coeficiente de torção $\left(\alpha_{e} 3,4\right)$, verificou-se que a variedade IAC 16, de tenacidade mais alta, produziu

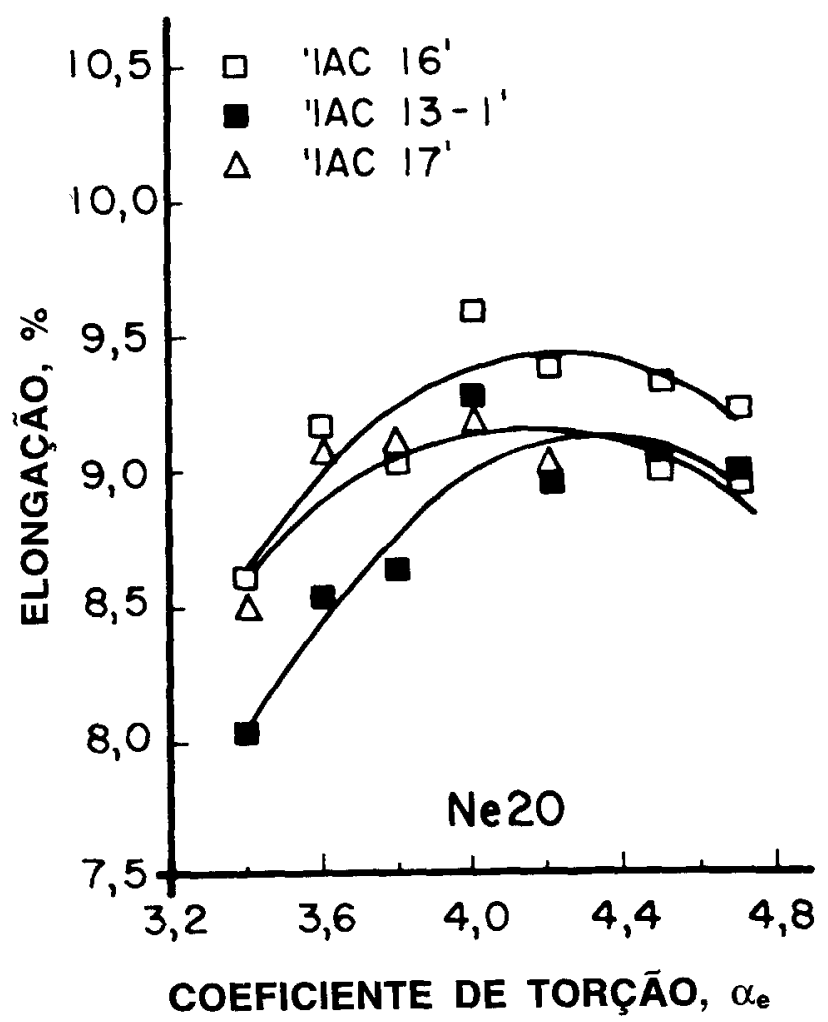

Figura 5. Representação gráfica das equações de regressão e valores experimentais para elongação, relativa ao título $\mathrm{Ne} 20$. 
fios de 22 até $32 \%$ mais resistentes do que a 'IAC 17'. Tendo em vista que o número de torções aplicadas aos fios aumenta com a utilização dos mais altos coeficientes, a diferença de tenacidade entre os fios produzidos pelas três variedades tornou-se progressivamente menor, no sentido do mais baixo para o mais alto coeficiente, conferindo aumentos ao algodão de maior tenacidade em relação àqueles de mais baixa tenacidade, na faixa de 18 a $23 \%$.

A máxima tenacidade dos fios produzidos pelas três variedades foi conseguida quando o coeficiente de torção variou de 3,91 a 4,36. Em geral, a torção necessária para a obtenção da tenacidade máxima aumentou muito pouco perante a gradação crescente dos títulos (Quadro 4). Resultados semelhantes foram registrados por Fiori et al. (1954): ao usar algodões com alta e com baixa tenacidade da fibra, concluíram que os primeiros produziram fios mais fortes, independentemente do título ou das torções que se thes conferissem.

As figuras 5, 6 e 7 mostram os efeitos, respectivamente, da tenacidade da fibra sobre a elongação dos fios de títulos Ne20, Ne30 e Ne40. A variedade IAC 16 produziu o fio mais elástico, seguida da 'IAC 17' e da 'IAC 13-1' para todos os títulos e coeficientes de torção. As curvas que representam torção-elongação foram similares, quadráticas, para as três variedades. No menor coeficiente de torção $\left(\alpha_{\mathrm{e}} 3,4\right)$, verifica-se uma tendência de aproximação entre os valores das variedades IAC 16 e IAC 17, porém um afastamento mediante coeficientes mais elevados, principalmente, no ponto de máxima elongação. A variedade IAC 13-1 apresentou os menores valores de elongação, situação inversa se compa-

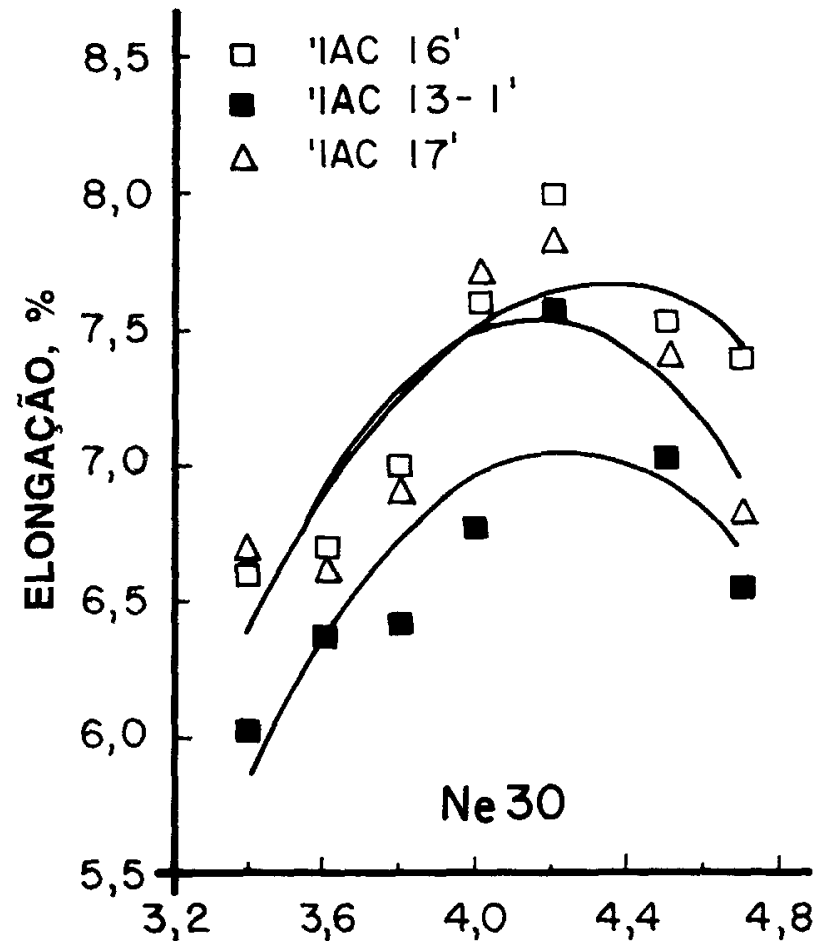

COEFICIENTE DE TORÇÃO, $\alpha_{e}$
Figura 6. Representação gráfica das equações de regressão e valores experimentais para elongação, relativa ao título Ne30.

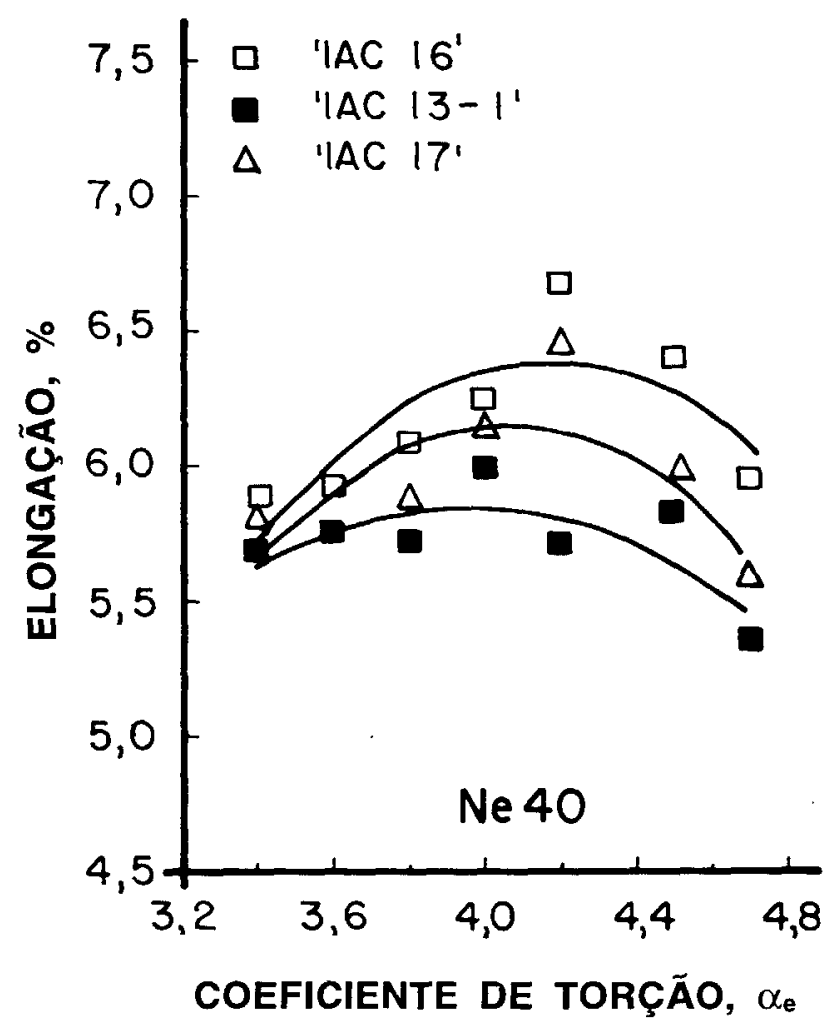

Figura 7. Representação gráfica das equações de regressão e valores experimentais para elongação, relativa ao título Ne40. 
rada à dos resultados de tenacidade do fio, na qual mostrou ser mais resistente que a 'IAC 17'. Essa inversão pode ser explicada pelo fato de a 'IAC 17' apresentar fibras mais elásticas. Tal esclarecimento tem como base informações obtidas nos laboratórios da Seção de Tecnologia de Fibras e contidas em trabalhos de Brown et al. (1957), pelos quais se conclui que a elongação dos fios de algodão é positivamente correlacionada com a elongação da fibra. Pelo exposto, admite-se que, havendo a referida correlação, deve-se fomentar o interesse e a importância da elongação da fibra em trabalhos de avaliação da influência de propriedades tecnológicas na qualidade do fio.

\section{CONCLUSÕES}

1. Fibras de algodão de alta tenacidade produzem fios mais resistentes para qualquer título ou torção.

2. A quantidade de torções requerida para a obtenção da máxima tenacidade dos fios singelos de algodão é pouco afetada pela tenacidade da fibra.

3. Maior tenacidade da fibra contribui para produzir fios mais elásticos.

4. Os fios de títulos mais altos, portanto mais finos, têm os menores valores de tenacidade e elongação.

5. A variedade IAC 16 apresentou fios com os maiores valores de tenacidade, seguida da 'IAC 13-1' e da 'IAC 17', e fios mais elásticos, acompanhada da 'IAC 17' e da 'IAC 13-1'.

\section{AGRADECIMENTOS}

Os autores expressam seu agradecimento à Fiação e Tecelagem Fides Ltda. e à Companhia Nacional de Estamparia (CIANÊ), pela colaboração prestada na execução deste trabalho.

\section{REFERÊNCIAS BIBLIOGRÁFICAS}

AMERICAN SOCIETY FOR TESTING AND MATERIALS. Standards on textile materials. $34^{\text {th }}$ ed. Philadelphia, 1963. 1008p.

BROWN, J.J.; HOWELL, N.A.; FIORI, L.A.; SANDS, J.E. \& LITTLE, H.W. Evaluation of the yarn properties of a high-strength interspecies cotton. Textile Research Journal, Lancaster, 27(4):332-339, 1957.

FIORI, L.A.; BROWN, J.J. \& SANDS, J.E. Effect of cotton fiber strength on single yarn properties and on processing behavior. Textile Research Journal, Lancaster, 24(6):504-507, 1954.

GRIDI-PAPP, I.L. \& SABINO, N.P. Maturidade da fibra de algodão determinada por processo óptico: método do fibrógrafo digital. Revista Brasileira de Tecnologia, Brasília, 3:99-106, 1972.

GROVE, E.B. \& HAMBY, D.S. Yarn numbering, yarn strength and analysis of strength measurements. In: HANDBOOK of testing and quality control. New York, Textile Book Publishers, 1960. p.317-399.

LANDSTREET, C.B. The relation of cotton fiber properties to spinning performance. In: COTTON IMPROVEMENT CONFERENCE, $7^{\text {th }}$ Greenville and Stoneville, 1954. Proceedings. 35p.

WEBB, R.W. \& RICHARDSON, H.B. Relationships between properties of cotton fibers and strength of carded yarn. Washington, D.C. Department of Agriculture, 1945. 58p. 